\title{
Charity Streaming: Why Charity Organizations Use Live Streams for Fundraising
}

\author{
Ankit Mittal \\ New Jersey Institute of \\ Technology \\ University Heights, GITC 5100 \\ Newark, NJ 07102 USA \\ am2272@njit.edu \\ Donghee Yvette Wohn \\ New Jersey Institute of \\ Technology \\ University Heights, GITC 5100 \\ Newark, NJ 07102 USA \\ wohn@njit.edu
}

Permission to make digital or hard copies of part or all of this work for personal or classroom use is granted without fee provided that copies are not made or distributed for profit or commercial advantage and that copies bear this notice and the full citation on the first page. Copyrights for third-party components of this work must be honored. For all other uses, contact the Owner/Author. CHIPLAY EA '19, October 22-25, 2019, Barcelona, Spain.

Copyright (C) 2019 is held by the owner/author(s)

ACM ISBN 978-1-4503-6871-1/19/10.

https://doi.org/10.1145/3341215.3356280

\begin{abstract}
Charity streaming is a novel and increasingly popular form of fundraising where content creators stream content during a fixed period of time to raise money and awareness. Many charity streams involve people playing games for a prolonged period of time. In this study, we interviewed charity organizations about what this new form of fundraising means for them and how it is different from traditional fundraising efforts.

\section{Author Keywords \\ live streaming; charity; fundraising; Tiltify; Twitch}

\section{Introduction}

On January 18, 2019, Harry Brewis, a Twitch streamer who goes by the name HBomberguy, decided to stream the entirety of the game Donkey Kong 64 to raise money for Mermaids, a charity that supports transgender kids [4]. While Brewis had raised $\$ 200,000$ after 50 hours of streaming, his stream really exploded when U.S. Congresswoman Alexandria Ocasio-Cortez (AOC) joined his chat and later called into his stream. $\mathrm{AOC}$ went on to talk about issues in the U.S at the time and to advocate equal rights for transgender people. Brewis finished his stream of Donkey Kong 64 after 57 hours and at the end had raised over $\$ 340,000$ for Mermaids.
\end{abstract}




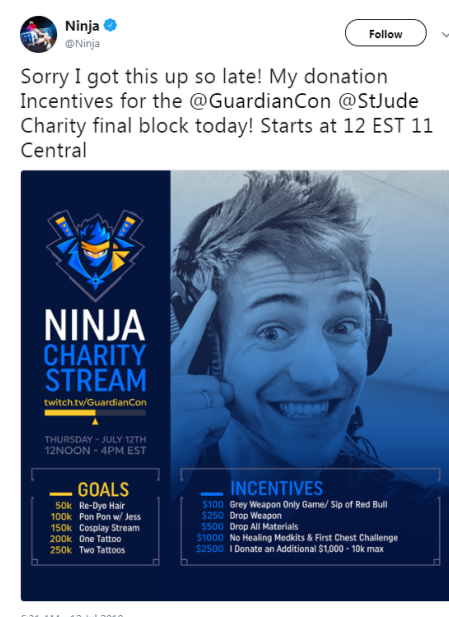

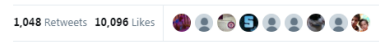

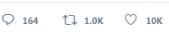

Figure 1: In this Tweet, streamer Ninja publicizes his charity stream, including some perks for those who donate.
Raising money for charity by playing and broadcasting games on live streams is becoming an increasingly widespread phenomenon.

On platforms like Twitch, the company itself runs initiatives where cheering ${ }^{1}$ with a charity hashtag will donate a portion of the bits to charity. More common, however, are individual or groups of streamers who create events during a set time frame to raise money for the charity of their choice. Some of these efforts are made by collaborations between the streamer and charity organization, or through charity events that are organized by third parties.

We have an understanding on why people donate to streamers from previous research. These reasons include paying for the entertainment, helping the streamer financially and improving the content, compensation for learning, emotional attachment to the streamer, desire for interaction, and to help solve social issues [7]. However, while we have an understanding of why people donate to streamers, we do not have an understanding of why organizations use live streaming platforms to raise money. In this paper we focus on why organizations are using live-streaming services as a method of fundraising and how it differs from their traditional fundraising methods. The information provided in this paper may influence the creation of better tools to support charity streaming. It may also serve as recommendations to other live streaming services to better incorporate donation methods on their platform.

\footnotetext{
${ }^{1}$ Cheering is a form of virtual support where viewers buy a virtual current called 'bits' with real money. They can then use these bits to purchase special emoticons to display in a streamer's chat. A portion of the money used to purchase the bits is given to the streamer.
}

\section{Background Information}

Twitch is a live streaming platform where people broadcast themselves doing activities such as playing video games. While Twitch is primarily focused on video game content, it is expanding to other creative areas as well such as music and art. Viewers can interact with the streamer and other viewers through a chat. Viewers can even donate or subscribe to a streamer if they really enjoy their content or want access to exclusive perks a streamer offers such as chat emotes [6]. Twitch has over 15 million unique daily viewers and $55 \%$ of Twitch users are in the age between $18-34^{2}$.

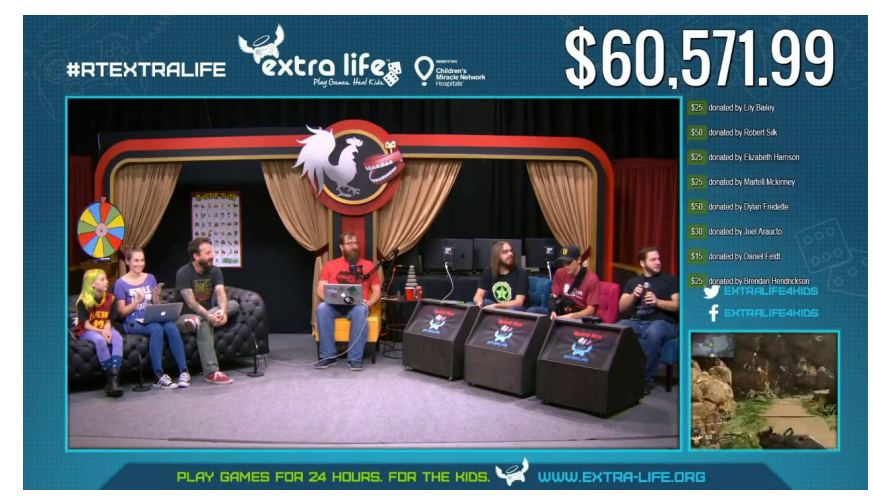

Figure 2: Rooster Teeth, a collection of gaming a comedy personalities, stream for 24 hours each year for the charity Extra Life. In between playing games, they also have variety show activities, such as a 'Wheel of Vengeance' where viewers can pay money to spin the wheel and make the team members do undesirable things, like eating peppercorns.

Many broadcasters on Twitch host streams where they decide to raise money for charities. Broadcasters will play games or do other activities and encourage friends, family,

\footnotetext{
${ }^{2}$ Twitch.tv
} 


\section{Terminology}

\section{Speedrunning}

Speedrunning is a term that is used to describe when someone plays a game from beginning to end as quickly as possible. It is a popular activity for charity streaming events.

\section{Gaming Marathon}

A gaming marathon is when one or more people play games for an extended period of time. Unlike running marathons, there is no rule about how long a gaming marathon should be, but commonly they start at 24 hours. Gaming marathons are commonly used in conjunction with charity streams. and random viewers to donate money to charity. There are events such as Extra Life where gamers will all stream on a particular day of the year, sometimes for 24 hours, with the goal of raising money for people in need [8].

Other charity events include Games Done Quick, which is held twice a year, where people attempt to beat different games as quickly as possible, often with challenges added on. Their most recent event in January 2019 raised over $\$ 2.4$ million for the Prevent Cancer Foundation. To date, Games Done Quick has raised over $\$ 19$ million for charity [1].

\section{Tiltify- Transaction Service for Direct Dona-} tions

Streamers have the option of either working directly with a charity to raise funds or by using a service known as Tiltify. Tiltify is partnered with a plethora of charities and allows users to safely and quickly donate to a charity without having to leave the stream the user is watching [3]. The service keeps track of how much money comes through the streamer, but since the streamer does not receive any of the money, the viewers can also receive receipts for their donation to the charity.

When streamers create a Tiltify account, they must select a charity they want to support, the start and end date of their campaign, and the goal they want to raise. They can then link their Twitch account, or any other streaming service, include their schedule, add incentives for viewers, and add milestones the streamer hopes to achieve. Finally, the streamer publishes the campaign and they receive a link to a web page that includes their stream, a button to donate, the progress the streamer has made towards their goal, and the name of the charity the streamer is supporting. When donating, users enter the amount they want to donate, their email, and can optionally choose to give their username or send a message to the streamer. If streamers do not use Tiltify, they can contact a charity and partner with them to have their own landing page where people can donate (cite: Tiltify).

Charity live streaming on Twitch has had huge success over the years. Between 2012 and 2017, Twitch has raised over $\$ 75$ million in donations for over 100 different charities [5] and $78 \%$ of Twitch users say they want more charity involvement in Twitch (cite: Twitch Advertising). With the rise of monthly Twitch viewers and more charity organizations using Twitch and partnering with big streamers, there is enormous potential in using Twitch for social good. Even with how massive Twitch is becoming, there has been little research on charity live streaming. In this study, we interviewed charity organizations that use Twitch with the following research questions:

RQ1) Why are charities using Twitch?

RQ2) How is Twitch different from traditional fundraising methods?

\section{Methods}

The information obtained in this study was from 10 to 20 minute-long semi-structured interviews conducted at TwitchCon 2018. TwitchCon is a convention dedicated to Twitch streamers and fans. This was the optimal location to collect data as many different charities were in attendance promoting their cause to people who stream and watch live streams. We interviewed 15 different spokespersons and recruiters of charity organizations who are deeply involved with Twitch (see sidebar). Questions ranged from "Why did your charity start using Twitch to raise awareness for your cause?" to "How big of an impact has Twitch made in reaching out to more people? As the 


\section{Charity Organizations That}

\section{We Interviewed:}

The AbleGamers Charity

\section{Extra Life}

Child's Play

Doctors Without Borders

Tiltify

Stack Up

To Write Love on Her Arms (TWLOHA)

American Foundation for Suicide Prevention

Call of Duty Endowment

Direct Relief

Make-A-Wish

Save the Children

St. Jude Children's Research Hospital

PLAYER vs. HUNGER

Wounded Warrior Project convention floor was very loud, we could not record the audio of the interviews. Upon completion of the interview, we quickly transcribed to the best of our ability.

To analyze the data, we organized the responses to the interview questions. We then went through all the responses together and sorted the answers into different categories. Finally, we selected the best quotes that would most accurately represent the categories.

\section{Why Charity Organizations Use Livestream- ing as a Fundraising Method}

For RQ1, we wanted to know why charity organizations were using Twitch.

\section{Public Relations/Marketing}

Most of the organizations we interviewed stated PR as the main reason they are using Twitch. Through Twitch,

charities can spread more awareness to their cause, reach a younger audience, and recruit more people to support their organization.

\section{Audience}

Twitch has millions of users from all around the world. These people range from little kids to elderly people, who come from all sorts of cultures and socioeconomic backgrounds. This type of diversity is very appealing to charity organizations as their message can reach new audiences that may not have been previously reachable.

Some charities are drawn to Twitch having a large amount of young users because reaching a younger audience is critical to their organizations. This is particularly the case for charities that were founded several decades ago. For example, according to a representative for Save the Children, their traditional donor base is aged 60-70 and they wanted to reach a younger audience. They tried marketing through TV, mail, and email but those methods were not effective in gathering new supporters. They decided to start fundraising through charity streaming on Twitch and were able to find success and are now hoping to grow even more. By attracting a new audience, the charity can expand their supporter demographic.

For the more established charity organizations, working with streamers on Twitch was seen as a long-term plan, because the actual money raised through streaming still represented less than $5 \%$ of their total fundraising efforts.

\section{Spread Awareness}

Most of the charity organizations that were interviewed said Twitch is a great platform to help spread awareness of their cause. When asked about why they are using Twitch, a representative from the American Foundation For Suicide Prevention said that they used live streaming as a means of fundraising because the demographic that watches steams coincides with the type of people they want to reach. "We want to raise awareness and tackle the stigma around discussing suicide. It's a new way of reaching out. In the age group of 15-34 suicide is the second leading cause of death. Awareness causes impact on perception, which is why we are trying to be more active on social media and streaming," they said. With teen and young adult suicide being a huge issue and Twitch having a predominantly younger audience, it is a good opportunity for organizations such as AFSP to connect with the Twitch community and educate people on suicide and its ramifications.

Many people may not be aware of or know enough about the issues people around the world are facing and now these organizations are leveraging the vast reach of Twitch to bring these issues to light. 


\section{Case Study: Extra Life}

Extra Life is an annual event that started in 2008 where people stream for 24 hours to raise money for sick kids in Children's Miracle Network Hospitals. Thousands of people across the world take part of Extra Life each year and have raised over $\$ 50$ million. The money raised is used for research, training, equipment, new facilities for the children, and more. ${ }^{3}$

\section{Case Study: Rooster Teeth}

The entertainment company Rooster Teeth gathers many employees for a massive stream where they play games and perform silly activities based on how much they have gathered in donations. They have raised over $\$ 5$ million in the past six years. Some of the money Rooster Teeth has raised went into the development of the Rooster Teeth Healing Garden in The Dell Children's Mental Health Unit in Austin, Texas.
When speaking to a representative from The AbleGamers Charity, the representative said their organization has spent years trying to convince video game developers to consider implementing options in their games that can benefit disabled gamers.

The main issue for them was that many developers and publishing companies did not know there are actually over 30 million disabled gamers in the world. Creating video games is expensive and it can take years to develop a game. Many companies do not want to spend time and money on features that most people will never use or need. As AbleGamers was able to spread their message around the industry and more research had been done in assistive technologies.

\section{Recruitment}

Many representatives of the organizations we interviewed said they starting using Twitch as a method to connect with and recruit other Twitch streamers to donate for them. Through platforms such as Tiltify, streamers who would like to contribute to a charity would be able to make a profile where any donation they get would go directly to the charity they are representing. By recruiting more people, there could be a network of streamers who do charity broadcasts on behalf of the organization. This creates exposure to new audiences.

Low Cost

Due to the cost of streaming being relatively low compared to other methods, charity organizations are adding Twitch as an extra avenue for spreading awareness. They are able to potentially reach a large amount of people with very little monetary cost to their organization. For example, To Write Love on Her Arms sends a representative to many concert festivals across the country. This is a fantastic way to engage with people but it adds a huge transportation cost and limits the amount of people you can reach to the size of the venue. With Twitch, there is no such cost as they can stream from anywhere and they have a reach of Twitch's 15 million unique daily users, much higher than that of a concert.

\section{How Charity Streaming is Different From Other Fundraising}

For RQ2, we wanted to know how Twitch was different from the charities traditional fundraising methods. The two main things that charities mentioned was how much charity streaming was initiated by the streamers and the ability to reach a large number of people.

\section{User Initiated}

Some charities such as St. Jude Children's Research Hospital said they actually started getting involved with Twitch because people reached out to their organization and asked them to. Traditionally, a charity would have to go around and promote their message on their own to get donations. Through Twitch, streamers across the world can decide to assist a charity and raise money on their behalf. Instead of the organization going out on their own to spread awareness, the community of streamers are out spreading awareness. With more streamers raising money for charities, it is likely others would follow suit and also decide to start raising money.

Reach

Many of the charities that were interviewed said Twitch's traffic of millions of viewers allows them to reach far more people than their traditional fundraising methods. The amount of people and diversity inside the Twitch community gives a better chance of someone discovering and supporting a charity they might connect with in some capacity. A representative from the AFSP said, "It's 


\section{Case Study: Ninja}

Richard Blevins, who goes by his online name Ninja, is a widely popular streamer who had over 14 million followers and an average viewer count of over 27,000 viewers on Twitch before moving exclusively to the streaming platform Mixer in early August. Blevins uses his huge popularity to host charity streams or compete in charity video game tournaments. He raised over $\$ 300,000$ for St. Jude Children's Research Hospital during a charity live streaming event at GuardianCon 2018. At E3 2018, Blevins competed in a $\$ 3$ million charity tournament with his partner Marshmello, a famous DJ, where they won the grand prize of $\$ 1$ million. Blevins donated his half of the money to the Alzheimer's Association [2]. These are just a couple of his many charity stream events. amazing how many people streaming can reach. A walk can be thousands of people but Ninja can reach millions."

\section{Discussion}

Despite the positive aspects of charity streaming, there are some limitations. From the perspective of the organizations, they have little control over the charity streams, since most streams are put together and run by streamers. While this is positive in that the organizations don't have to put in the effort, it also means they do not have control over the content that is being streamed, as well as who chooses to host a charity stream, which could become problematic if someone who represents or advocates values that are counter to the organization decides to stream in the name of the charity. Another limitation is that because charity streams are organized around the streamers and viewers donate to the charity because of the streamer, it is unclear if the donors would still donate if it were not for the streamer. Charity streaming is such a new phenomenon and still a relatively smaller portion in terms of the total amount of money raised for many charities that they have not been able to look at metrics of donors across the years. Another factor related to the streamer-centric aspect of charity streams is that there are currently few ways for viewers/potential donors to search for stream by charity unless the stream is part of a larger event that is promoted by Twitch.

To better understand the phenomena of contributing to charities via live streams, future studies could conduct interviews with donors and charity live streamers to understand their motivations. Furthermore, more research could be done on understanding what makes a successful charity stream. Our research was very broad. Future research can narrow down types of charity streams to see what connects more with viewers or raises more money.

\section{Conclusion}

Charity streaming is a relatively new but growing method of fundraising. In interviews with charity organizations, we found that streaming represents revenue that did not exist before and the cost for organizing charity streaming events is minimal for the organizations.

\section{Acknowledgements}

Thanks to John Scott Siri and Juan Rios. Partially funded by NSF 1841354

\section{References}

[1] Gray, K. Awesome games done quick ends with $\$ 2.3$ million raised for charity. Kotaku (2019).

[2] Gutelle, S. fortnite streamer ninja helped floridas guardiancon raise $\$ 2.7$ million for st. jude. Tubefilter (2018).

[3] Lum, P. 'geek philanthropy': the gamers raising millions through marathon live streams. The Guardian (2019).

[4] McWhertor, M. How alexandria ocasio-cortez wound up on a donkey kong 64 twitch charity stream. Polygon (2019).

[5] Schroeder, A. 2017 charity update: Twitch community gives back at record pace! Twitch.tv (2017).

[6] Stephenson, B. Twitch: Everything you need to know. Lifewire (2019).

[7] Wohn, D. Y., Freeman, G., and McLaughlin, C. Explaining viewers' emotional, instrumental, and financial support provision for live streamers. In Proceedings of the $2018 \mathrm{CHI}$ conference on human factors in computing systems, ACM (2018), 474.

[8] Woolfenden, N. Live streaming for social good: How twitch is transforming the charity fundraiser. 